\title{
Endoscopic endonasal transclival resection of a ventral pontine cavernous malformation: technical case report
}

\author{
Juan Luis Gómez-Amador, MD, ${ }^{1}$ Luis Alberto Ortega-Porcayo, MD, ${ }^{1}$ Isaac Jair Palacios-Ortíz, MD,1 \\ Alexander Perdomo-Pantoja, MD, ${ }^{1}$ Felipe Eduardo Nares-López, MD, ${ }^{1}$ and \\ Alfredo Vega-Alarcón, MD2,3
}

\begin{abstract}
Departments of ${ }^{1}$ Neurological Surgery and ${ }^{2}$ Neuro-otology, Instituto Nacional de Neurología y Neurocirugía "Manuel Velasco Suárez"; and "Department of Neurotology, Neurological Center, American British Cowdry Hospital, Santa Fe Campus, Mexico City, Mexico
\end{abstract}

\begin{abstract}
Brainstem cavernous malformations are challenging due to the critical anatomy and potential surgical risks. Anterolateral, lateral, and dorsal surgical approaches provide limited ventral exposure of the brainstem. The authors present a case of a midline ventral pontine cavernous malformation resected through an endoscopic endonasal transclival approach based on minimal brainstem transection, negligible cranial nerve manipulation, and a straightforward trajectory. Technical and reconstruction technique advances in endoscopic endonasal skull base surgery provide a direct, safe, and effective corridor to the brainstem.
\end{abstract}

https://thejns.org/doi/abs/10.3171/2016.8.JNS161137

KEY WORDS brainstem; cavernous malformation; endonasal; endoscopic; transclival; diagnostic technique

$\mathrm{C}$ EREBRAL cavernous malformations (CMs) are characterized by abnormally dilated vascular channels lined by a single layer of endothelium., 3,7,923 They lack normal vessel wall elements and brain parenchyma. ${ }^{5}$ Their prevalence is estimated to be $0.4 \%-0.6 \%{ }^{9}$ Brainstem cavernous malformations (BSCMs) account for $18 \%{ }^{9}$ of intracranial CMs and, despite their low flow and low pressure, their hemorrhage rates are higher than those of supratentorial $\mathrm{CMs}$, with a bleeding rate of $1.6 \%-3.1 \%{ }^{14,17,20}$ per patient-year and a rebleeding rate of $4.5 \%-22.9 \%$ per patient-year. ${ }^{1,14}$ BSCMs are challenging because of the critical anatomy and potential surgical risks. Minimizing pial incision and brainstem transection is the main consideration when deciding the optimal surgical approach for each patient. We present a case of a midline ventral pontine CM that was resected through an endoscopic endonasal transclival approach that allowed for minimal brainstem transection, negligible cranial nerve (CN) manipulation, and a straightforward trajectory.

\section{Case Report}

Presentation and Examination

A 29-year-old man presented with acute occipital headache, nausea, and horizontal diplopia. Five days later, he developed somnolence, facial palsy, dysarthria, dysphonia, dysphagia, and left hemiparesis. The patient was transferred to our emergency department in acute respiratory failure, and ventilatory support was provided. CT scanning demonstrated acute pontine bleeding, and MRI demonstrated a $1.8 \times 2.6 \times 2.9-\mathrm{cm}$ ventral pontine CM (Fig. 1). The patient was diagnosed with aspiration pneumonia and was treated in the intensive care unit with $1 \mathrm{~g}$ cefepime 3 times per day and $100 \mathrm{mg}$ tigecycline 2 times per day for 20 days. Tracheostomy and gastrostomy were performed, and the patient remained under observation until the pneumonia resolved. Forty days after admission, examination revealed normal consciousness, right trigeminal hypesthesia, abduction limitation of the right eye, facial palsy (HouseBrackmann Grade IV), and decreased gag reflex. Motor examination revealed 0/5 strength in the left upper and lower extremities, hyperreflexia, and Babinski sign. After offering and discussing resection versus conservative medical treatment, the patient opted for surgical treatment. His preoperative modified Rankin Scale (mRS) score was 4.

\section{Operation}

The surgical approach was dictated by the location of the $\mathrm{CM}$ to minimize neural tissue transection and avoid

ABBREVIATIONS AICA = anterior inferior cerebellar artery; $\mathrm{BSCM}=$ brainstem CM; $\mathrm{CM}=$ cavernous malformation; $\mathrm{CN}=\mathrm{cranial}$ nerve; $\mathrm{mRS}=$ modified Rankin Scale. SUBMITTED May 20, 2016. ACCEPTED August 1, 2016.

INCLUDE WHEN CITING Published online October 21, 2016; DOI: 10.3171/2016.8.JNS161137. 

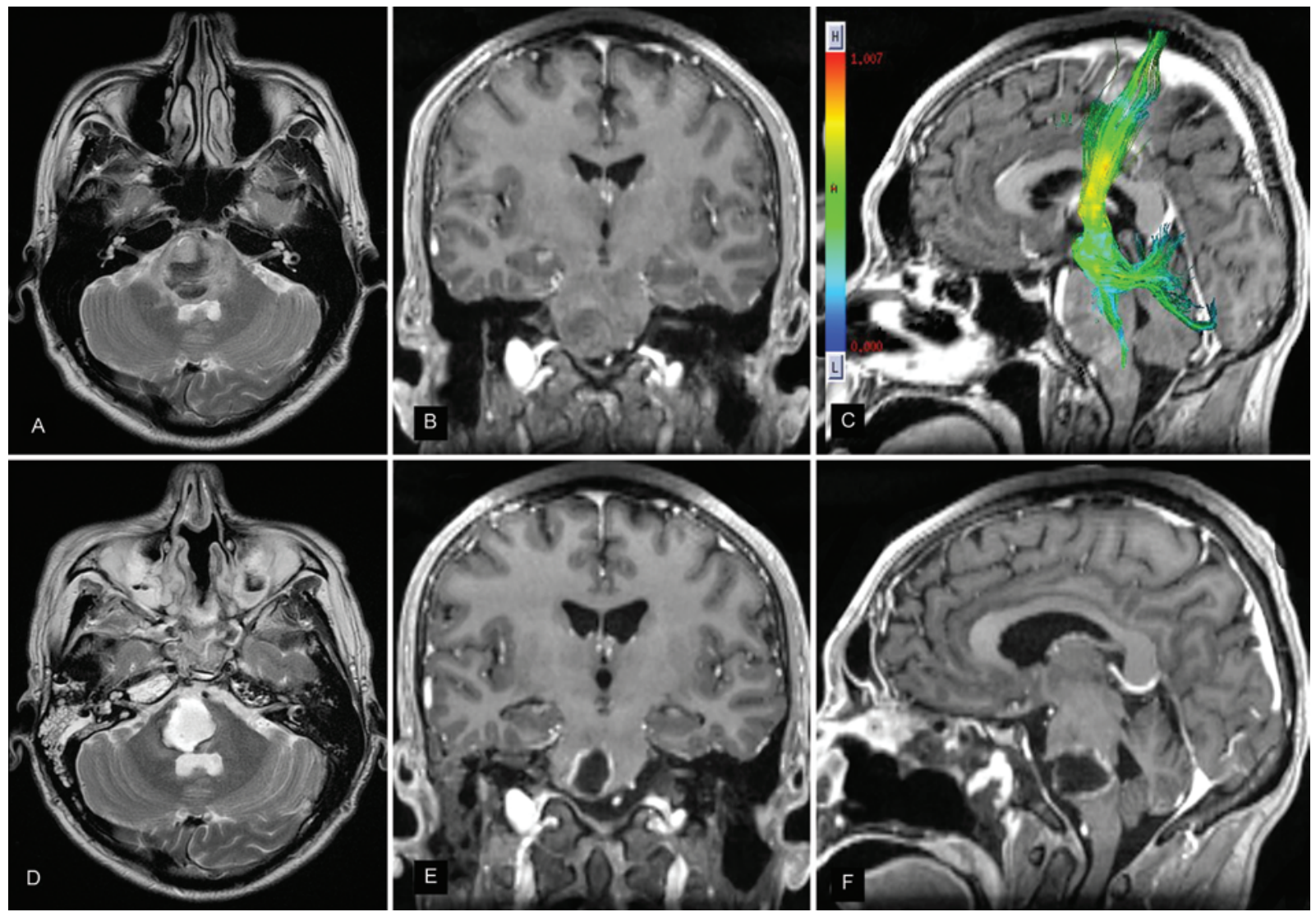

FIG. 1. A-C: Preoperative axial, coronal, and sagittal MR images showing a $1.8 \times 2.6 \times 2.9-\mathrm{cm}$ ventral pontine $\mathrm{CM}$. Notice the preoperative tractography $(\mathrm{C})$ of the corticospinal tracts displaced posteriorly by the CM. D-F: Postoperative MR images obtained 5 days later, showing gross-total resection. Figure is available in color online only.

the corticospinal tracts. The best surgical corridor was determined using the "2-point method," placing one point in the center of the lesion and a second point in the border closer to the pial surface. The resultant straight line suggested a central approach. Tractography was performed (Fig. 1C), which revealed posterior displacement of the corticospinal tract. Based on the clinical findings, the 2-point method, and the tractography findings, we decided that the patient would benefit from an endonasal endoscopic transclival approach.

The neuroanesthesiology team inserted an armored oral endotracheal tube and induced total intravenous anesthesia. The patient was placed supine with his head fixed in a Mayfield head holder with $20^{\circ}$ of flexion and turned $10^{\circ}$ toward the surgeon. Patient registration was done using a stereotactic navigation guidance system (StealthStation S7, Medtronic). The endoscope $\left(0^{\circ}\right.$ and $45^{\circ}, 18 \mathrm{~cm} \times 4$ $\mathrm{mm}$ ) was attached to a high-definition camera with an irrigating sheath. Endoscopic and navigation monitors were placed cephalad to the patient. The patient's nose was prepared by applying oxymetazoline solution. We used a bilateral nostril approach and a 2-surgeon technique without endoscopic holders. The middle turbinates were displaced laterally, and a right nasoseptal flap was dissected following the sphenopalatine artery. The nasoseptal flap was hidden in the right choana inferiorly. The sphenoid ostium was opened, and wide bilateral sphenoidotomies were performed; the posterior septum was detached carefully in a large piece for reconstruction. Paraclival carotid arteries and vidian canals were identified using navigation. Nasopharyngeal mucosa and midline fascia were opened with the aid of monopolar electrocautery. High-speed (cutting and diamond) drills were used to remove the mid- and superior portion of the lower clivus; lateral drilling was limited by the paraclival carotid arteries (Fig. 2). The dura was opened in the midline. The basilar artery and the right anterior inferior cerebellar artery (AICA) were observed initially. There was a minimal discoloration of the pons above the AICA, and a small incision was made with neuronavigation assistance (Fig. 3). The CM was resected using dissectors, curettes, biopsy forceps, and gentle aspiration. Care was taken to remove the $\mathrm{CM}$ completely without the gliotic, hemosiderin-stained margin. After total resection, hemostasis was achieved using Floseal hemostatic matrix (Baxter Healthcare Corp.). The surgical field and anatomical relationships were inspected using a $45^{\circ}$ endoscope. Collagen matrix (DuraGen, Integra Neurosciences) was placed under and above the dura mater, and autologous fascia lata was harvested from the anterior left lateral thigh and placed extradurally. A piece of posterior septum was fashioned to the shape of the drilled clivus and was placed to support the fascia (gasket seal 

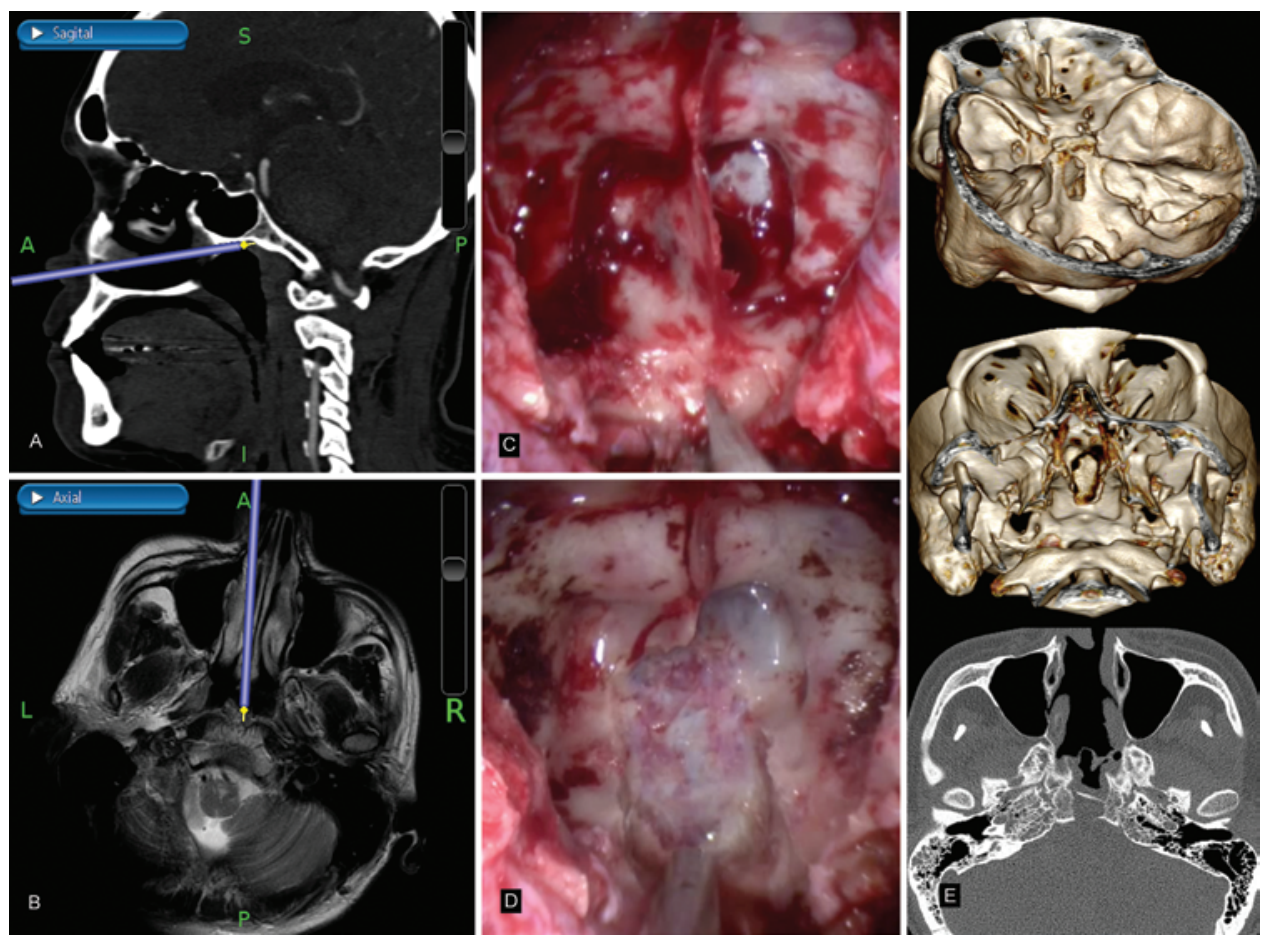

FIG. 2. A and B: A stereotactic navigation guidance system is used to localize the site for the focal clivectomy. C and D: Intraoperative images of the clivus before (C) and after (D) drilling of the mid- and superior part of the lower clivus. E: Postoperative CT $3 \mathrm{D}$ reconstruction of the focal clivectomy. Notice the gasket seal technique in which a piece of the posterior septum was fashioned to the shape of the drilled clivus. Figure is available in color online only.

technique). The nasoseptal flap was elevated and placed covering the surgical defect. Fibrin tissue adhesive sealant (Beriplast, Aventis Behring) was used to seal the surgical defect, and the balloon from a Foley catheter was placed to hold the flap (Video 1).

VIDEO 1. Endonasal endoscopic pontine cavernoma resection. Surgical technique for the resection of a pontine cavernous malformation using an endoscopic endonasal transclival approach. BA = basilar artery; ET = eustachian tube; IT = inferior turbinate; $\mathrm{MT}=$ middle turbinate; NSF = nasoseptal flap; SUCA = superior cerebellar artery. Copyright Juan Luis Gómez-Amador. Published with permission. Click here to view.

\section{Postoperative Course}

The surgical time was 230 minutes and the blood loss was $400 \mathrm{ml}$. Immediately after surgery, the patient was awake and ventilatory support was removed 4 hours later. Palate deviation improved, and a soft diet was started 3 days after surgery. The Foley balloon was removed from the nose 5 days after surgery. Tracheostomy and gastrostomy tubes were removed 1 month after surgery. By 5 months after surgery, the patient's left leg strength (4/5) and cranial nerve $(\mathrm{CN})$ VI and VII function had improved. His latest mRS score improved to 2 . MRI performed 5 days after surgery demonstrated a gross-total resection (Fig. 1D-F).

\section{Discussion}

Approaches to pontine CMs vary according to the precise location based on the closest pial entry point and the safer entry zone. According to Mai et al. ${ }^{16}$ surgical approaches to the pons can be divided into 4 categories: dorsal, anterolateral, lateral, and central. Patients with ventral pons CMs have better results than their counterparts with dorsal lesions because anterolateral approaches have safer entry zones, ${ }^{8}$ avoiding injury of the floor of the fourth ventricle (medial longitudinal fasciculus, facial, and abducens nuclei), when using a dorsal telovelar approach. ${ }^{2,26}$ However, to obtain an anterolateral trajectory from a retrosigmoid approach, ample retraction of the cerebellum is required, but it gives a limited ventral exposure of the pons. To overcome this problem, a retrosigmoid suprafloccular transhorizontal fissure approach ${ }^{19}$ provides adequate access to the triangular peritrigeminal entry zone, which is bound medially by the pyramidal tract, laterally by the root entry zone of the trigeminal nerve, and inferiorly by the pontomedullary sulcus out to the flocculus. ${ }^{16,21}$ Lateral approaches like the anterior transpetrosal approach ${ }^{12}$ or a presigmoid approach ${ }^{10,25}$ provide a more direct and wider exposure of the ventral pons, but could result in hearing loss. CMs situated in the ventral midline surface benefit from a central transclival approach. Reisch et al. ${ }^{22}$ first successfully treated a ventral CM using a transoral transclival approach; however, the outcome of transoral surgery has been complicated by CSF leaks and meningitis. Mai et al. ${ }^{16}$ advocated for a transmaxillary-transclival approach for these rare midline ventral cases; they reported 1 case using this approach in a woman whose mRS score improved after the surgery, but unfortunately the CM recurred. Endoscopic endonasal approaches offer several 

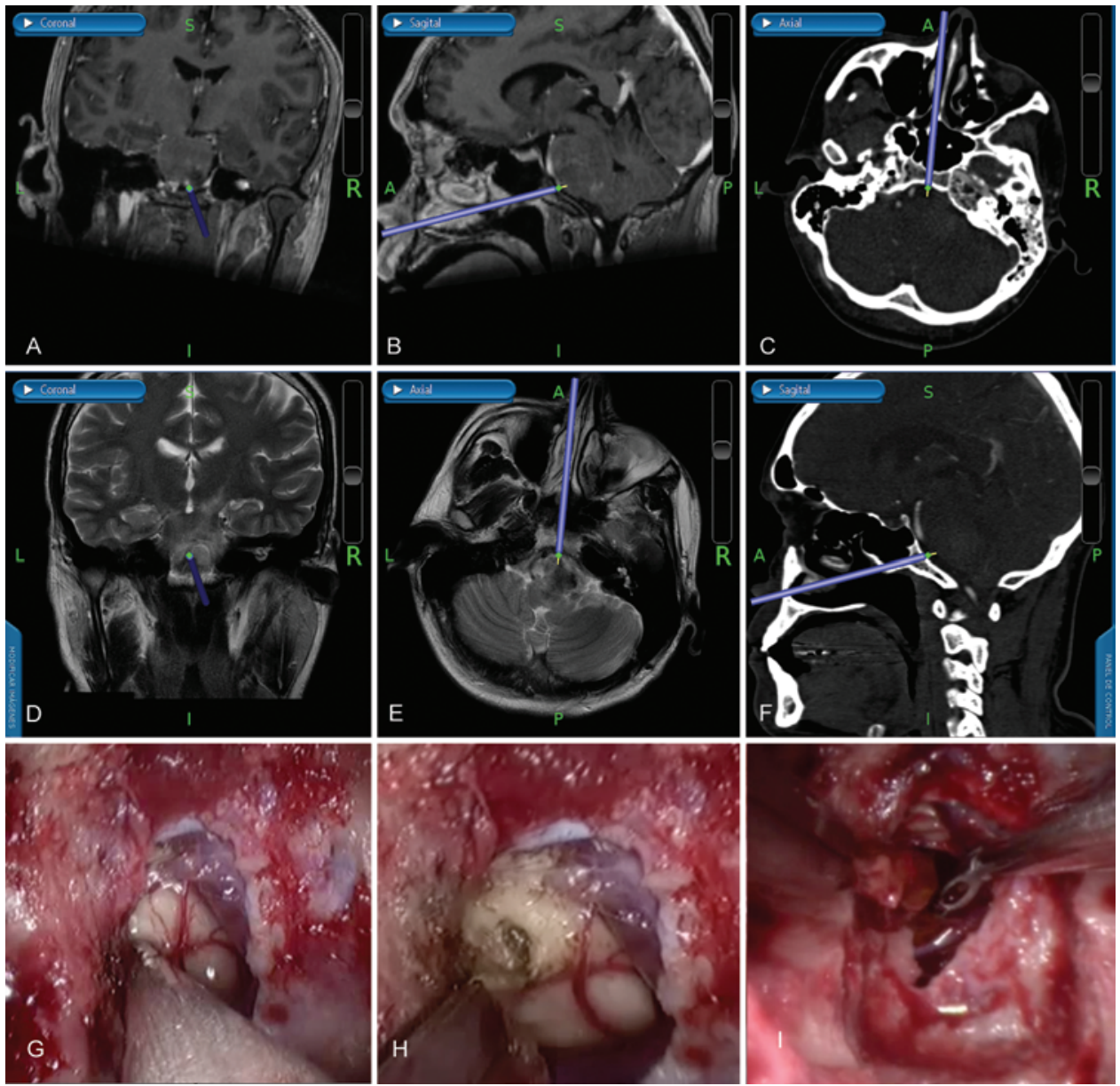

FIG. 3. A-F: A stereotactic navigation guidance system is used to localize the precise site for the pontine incision. $\mathbf{G}$ and $\mathrm{H}$ : Excellent accuracy is usually obtained for the skull base and the brainstem. The incision was performed above the AICA and at the right of the basilar artery. I: A 2-surgeon/2-handed technique was performed to completely remove the CM. Figure is available in color online only.

advantages: natural nasal and paranasal air spaces permit accessing the skull base in a straightforward manner, thereby avoiding skin incisions and maxillofacial transpositions, causing minimal brain and cranial nerve manipulation, preserving neurological and masticatory functions, and achieving better cosmetic results. The main previous limitations of endonasal endoscopy have been overcome with better endoscopes, the routine use of neuronavigation, and better reconstruction techniques that prevent CSF leaks and infection-related complications. Recently, 5 different groups published case reports of endonasal endoscopic resection of ventral BSCMs ${ }^{6,11,13,15,18,24}$ ( 1 from the midbrain, 4 from the pons, and 1 from the medulla), demonstrating that the endonasal endoscopic transclival approach is a viable and effective corridor for the ventral brainstem (Table 1).

The main concern using endoscopic endonasal approaches for intradural lesions is the potential risk of a CSF leak; however, the CSF leaks that were reported previously $^{13,24}$ were successfully treated with revision of the nasoseptal flap in a second surgery, and no infection-related complications were reported. No CSF leakage has been documented in the last 5 case reports, which shows that reconstruction techniques are significantly improving. In our experience, intradural cases need a gasket seal closure and a vascularized pedicle nasoseptal flap multilayered reconstruction technique, which decrease the occurrence of postoperative CSF leaks (Video 1). Aggressive postoperative lumbar CSF drainage has been advocated to reduce the risk of CSF leakage, ${ }^{15}$ however, we do not routinely perform postoperative CSF drainage, and in this case no CSF leak was documented. Usually, we reserve aggressive CSF drainage for the treatment of primary CSF leaks, previous reconstruction failure, and after reconstruction of extensive skull base defects.

When planning a transclival approach to the brainstem, it is important to ensure that the instrumentation length is sufficient to reach the surgical target. Our instruments are specially designed for the sellar region; in this case, the manipulation of the dorsal portion of the $\mathrm{CM}$ was more challenging because the instruments were not long enough. The design of a special set of endoscopic instruments for the brainstem and the craniovertebral junction will be useful for future cases. 
TABLE 1. Endoscopic endonasal transclival approach to ventral BSCMs

\begin{tabular}{|c|c|c|c|c|c|}
\hline $\begin{array}{l}\text { Authors } \\
\text { \& Year }\end{array}$ & $\begin{array}{l}\text { Size } \\
(\mathrm{cm})\end{array}$ & $\begin{array}{l}\text { Age (yrs), } \\
\quad \text { Sex }\end{array}$ & $\begin{array}{l}\text { Extent of } \\
\text { Resection }\end{array}$ & Complication & Follow-Up \\
\hline \multicolumn{6}{|l|}{ Medulla } \\
\hline Nayak et al., 2015 & $0.8 \times 0.9 \times 1$ & $60, \mathrm{~F}$ & Total & & 3 mos; no improvement \\
\hline \multicolumn{6}{|l|}{ Pons } \\
\hline $\begin{array}{l}\text { Sanborn et al., } 2012 \& \\
\quad \text { Nayak et al., } 2015\end{array}$ & $1.7 \times 1.2$ & $17, \mathrm{M}$ & Total & CSF leak & $\begin{array}{l}24 \text { mos; motor strength improvement } 4 / 5 \text {, sural graft for } \\
\text { facial palsy \& ocular symptoms improved considerably }\end{array}$ \\
\hline Kimball et al., 2012 & $2 \times 2 \times 2$ & $59, \mathrm{~F}$ & Total & CSF leak & 1 mo; improvement of CN VII palsy \& strength $4 / 5$ \\
\hline Dallan et al., 2015 & $1 \times 1$ & $15, \mathrm{M}$ & Subtotal & & 24 mos; improvement of CN VI, VII, \& VIII palsy \\
\hline Linsler \& Oertel, 2015 & $2 \times 1.8 \times 2$ & $19, \mathrm{~F}$ & Total & & 6 wks; no deficit \\
\hline Present case & $1.8 \times 2.6 \times 2.9$ & $29, M$ & Total & & $\begin{array}{l}5 \text { mos; motor strength improvement } 3 / 5 \text { \& partial recovery } \\
\text { of CN VI \& VII palsy }\end{array}$ \\
\hline \multicolumn{6}{|l|}{ Midbrain } \\
\hline He et al., 2016 & $1.2 \times 1.7$ & $20, F$ & Total & & 3 mos; no deficit \\
\hline
\end{tabular}

Surgical results from these 7 case reports have been promising. Gross-total resection was achieved in 6 of 7 cases (85\%), which is similar to the $91 \%$ (1390 cases) reported from a microsurgical BSCM meta-analysis. ${ }^{8}$ No clinical deficit was observed after surgery in 2 patients, significant clinical improvement was seen in 4 patients, and there was no improvement in 1 patient (Table 1). Clinical condition was improved or the same in $100 \%$ of the endonasal endoscopic case reports, which is better than the $84 \%$ reported from a meta-analysis. ${ }^{8}$ The overall surgical and/or CM-related mortality rate was $0 \%$ in comparison with the $1.5 \%$ presented by Gross et al. ${ }^{8}$ The main objective of this report is to highlight the favorable results for these rare midline ventral CMs using an endonasal endoscopic approach.

\section{Conclusions}

We have described our surgical technique for the successful resection of a ventral pontine CM using an endonasal focal transclival approach and reconstruction using the gasket seal multilayered reconstruction technique. This approach offers minimal brainstem transection, negligible cranial nerve manipulation, and a direct trajectory to the ventral brainstem.

\section{Acknowledgments}

Thanks to our helpful and efficient nursing, ENT, and neuroanesthesiology teams. A special thanks to Karla Ortega and Francisco Rivero for proofreading and editing this article.

\section{References}

1. Aiba T, Tanaka R, Koike T, Kameyama S, Takeda N, Komata T: Natural history of intracranial cavernous malformations. J Neurosurg 83:56-59, 1995

2. Asaad WF, Walcott BP, Nahed BV, Ogilvy CS: Operative management of brainstem cavernous malformations. Neurosurg Focus 29(3):E10, 2010

3. Awad IA, Robinson JR Jr, Mohanty S, Estes ML: Mixed vascular malformations of the brain: clinical and pathogenetic considerations. Neurosurgery 33:179-188, 1993
4. Brown A, Thompson B, Spetzler R: The two-point method: evaluating brainstem lesions. BNI Q 12:20-24, 1996

5. Clatterbuck RE, Eberhart CG, Crain BJ, Rigamonti D: Ultrastructural and immunocytochemical evidence that an incompetent blood-brain barrier is related to the pathophysiology of cavernous malformations. J Neurol Neurosurg Psychiatry 71:188-192, 2001

6. Dallan I, Battaglia P, de Notaris M, Caniglia M, TurriZanoni M: Endoscopic endonasal transclival approach to a pontine cavernous malformation: case report. Int $\mathbf{J}$ Pediatr Otorhinolaryngol 79:1584-1588, 2015

7. Del Curling O Jr, Kelly DL Jr, Elster AD, Craven TE: An analysis of the natural history of cavernous angiomas. J Neurosurg 75:702-708, 1991

8. Gross BA, Batjer HH, Awad IA, Bendok BR, Du R: Brainstem cavernous malformations: 1390 surgical cases from the literature. World Neurosurg 80:89-93, 2013

9. Gross BA, Lin N, Du R, Day AL: The natural history of intracranial cavernous malformations. Neurosurg Focus 30(6):E24, 2011

10. Hauck EF, Barnett SL, White JA, Samson D: The presigmoid approach to anterolateral pontine cavernomas. Clinical article. J Neurosurg 113:701-708, 2010

11. He SM, Wang Y, Zhao TZ, Zheng T, Lv WH, Zhao LF, et al: Endoscopic endonasal approach to mesencephalic cavernous malformations. World Neurosurg 90:701.e7-701.e10, 2016

12. Kawase T, Toya S, Shiobara R, Mine T: Transpetrosal approach for aneurysms of the lower basilar artery. J Neurosurg 63:857-861, 1985

13. Kimball MM, Lewis SB, Werning JW, Mocco JD: Resection of a pontine cavernous malformation via an endoscopic endonasal approach: a case report. Neurosurgery 71 (1 Suppl Operative): 186-194, 2012

14. Kondziolka D, Lunsford LD, Kestle JR: The natural history of cerebral cavernous malformations. J Neurosurg 83:820 824, 1995

15. Linsler S, Oertel J: Endoscopic endonasal transclival resection of a brainstem cavernoma: a detailed account of our technique and comparison with the literature. World Neurosurg 84:2064-2071, 2015

16. Mai JC, Ramanathan D, Kim LJ, Sekhar LN: Surgical resection of cavernous malformations of the brainstem: evolution of a minimally invasive technique. World Neurosurg 79:691-703, 2013

17. Moriarity JL, Wetzel M, Clatterbuck RE, Javedan S, Sheppard JM, Hoenig-Rigamonti K, et al: The natural history of 
cavernous malformations: a prospective study of 68 patients. Neurosurgery 44:1166-1173, 1999

18. Nayak NR, Thawani JP, Sanborn MR, Storm PB, Lee JY: Endoscopic approaches to brainstem cavernous malformations: Case series and review of the literature. Surg Neurol Int 6:68, 2015

19. Ohue S, Fukushima T, Friedman AH, Kumon Y, Ohnishi T: Retrosigmoid suprafloccular transhorizontal fissure approach for resection of brainstem cavernous malformation. Neurosurgery 66 (6 Suppl Operative):306-313, 2010

20. Porter PJ, Willinsky RA, Harper W, Wallace MC: Cerebral cavernous malformations: natural history and prognosis after clinical deterioration with or without hemorrhage. J Neurosurg 87:190-197, 1997

21. Recalde RJ, Figueiredo EG, de Oliveira E: Microsurgical anatomy of the safe entry zones on the anterolateral brainstem related to surgical approaches to cavernous malformations. Neurosurgery 62 (3 Suppl 1):9-17, 2008

22. Reisch R, Bettag M, Perneczky A: Transoral transclival removal of anteriorly placed cavernous malformations of the brainstem. Surg Neurol 56:106-116, 2001

23. Robinson JR, Awad IA, Little JR: Natural history of the cavernous angioma. J Neurosurg 75:709-714, 1991

24. Sanborn MR, Kramarz MJ, Storm PB, Adappa ND, Palmer JN, Lee JY: Endoscopic, endonasal, transclival resection of a pontine cavernoma: case report. Neurosurgery 71 (1 Suppl Operative):198-203, 2012

25. Seifert V, Raabe A, Zimmermann M: Conservative (labyrinth-preserving) transpetrosal approach to the clivus and petroclival region-indications, complications, results and lessons learned. Acta Neurochir (Wien) 145:631-642, 2003

26. Ziyal IM, Sekhar LN, Salas E, Sen C: Surgical management of cavernous malformations of the brain stem. Br J Neurosurg 13:366-375, 1999

\section{Disclosures}

The authors report no conflict of interest concerning the materials or methods used in this study or the findings specified in this paper.

\section{Author Contributions}

Conception and design: Gómez-Amador. Acquisition of data: Ortega-Porcayo, Palacios-Ortíz, Perdomo-Pantoja, Nares-López, Vega-Alarcón. Analysis and interpretation of data: all authors. Drafting the article: Gómez-Amador, Ortega-Porcayo. Critically revising the article: all authors. Reviewed submitted version of manuscript: Gómez-Amador, Ortega-Porcayo, Palacios-Ortíz, Perdomo-Pantoja, Nares-López. Approved the final version of the manuscript on behalf of all authors: Gómez-Amador. Administrative/technical/material support: Vega-Alarcón.

\section{Supplemental Information Videos \\ Video 1. https://vimeo.com/179463212.}

\section{Correspondence}

Juan Luis Gómez-Amador, Department of Neurological Surgery, Instituto Nacional de Neurología y Neurocirugía "Manuel Velasco Suárez," Insurgentes Sur 3877, Colonia la Fama. Delegación Tlalpan, Ciudad de México, ZC 14269, México. email: jlga@ neurocirugia-innn.com. 